\title{
Inhibitory Effects of Brazilian Propolis on Lipid Accumulation in 3T3-L1 Cells
}

\author{
Yasuhito Nobushi ${ }^{*}, 1$, Naoki Oikawa1, Yuzo Okazaki², Shigetoshi Tsutsumi², \\ Yong Kun Park ${ }^{3}$, Masahiko Kurokawa ${ }^{4}$ and Ken Yasukawa ${ }^{1}$ \\ ${ }^{1}$ School of Pharmacy, Nihon University, 7-7-1, Narashinodai, Funabashi-shi, Chiba 274-8555, Japan \\ ${ }^{2}$ Amazonfood Ltd., 3-1-8, Misaki, Chiyoda, Tokyo 101-0061, Japan \\ ${ }^{3}$ Department of Food Science, College of Food Engineering, State University of Campinas, Campinas, SP, \\ Brazil \\ ${ }^{4}$ Department of Biochemistry, Graduate School of Clinical Pharmacy, Kyushu University of Health and \\ Welfare, 1714-1 Yoshino, Nobeoka, Miyazaki 882-8508, Japan
}

\begin{abstract}
We here investigated the inhibitory effect of Brazilian propolis on intracellular lipid accumulation. Seven ethanolic extracts of Brazilian propolis were tested for their inhibitory effect on intracellular lipid accumulation in 3T3-L1 cells. Among the seven Brazilian propolis, the extracts AF-08 and AF-18 had inhibitory effects on intracellular lipid accumulation. In particular, the Brazilian propolis AF-08 exhibited a potential inhibitory effect on intracellular lipid accumulation. Thus, these results suggest that the Brazilian propolis AF-08 contributes to the prevention of metabolic syndrome. In addition, five known triterpenoids were isolated from the Brazilian propolis AF-08: betulonic acid, moronic acid, 3-oxo oleanolic acid, masticadienonic acid, and anwnweizonic acid. Four of the triterpenoids exhibited an inhibitory effect on intracellular lipid accumulation. Thus, these triterpenoids may be important as antiobesity agents that inhibit the metabolic syndrome.
\end{abstract}

Keywords: Brazilian propolis, 3T3-L1 cells, lipid accumulation, triterpenoids.

\section{INTRODUCTION}

Propolis is a resinous material collected by honeybees from various buds and exudates of plants, which is used to protect the beehive from external enemies. Propolis has been widely used in folk medicine since $300 \mathrm{BC}$ because of its varied chemical composition [1, 2]. It is well known that the constituents of propolis depend on its plant origin and the time of collection [3]. Numerous biological properties of propolis have been reported, including antibacterial [4], antiviral [5], anti-inflammatory [6], antitumor [7], and antioxidant activities [8-10]. In Japan, Brazilian propolis extracted by ethanol has been extensively used in food to improve health and prevent diseases such as gingivitis, rheumatism, cold, and cancer.

Obesity is a serious health problem in industrialized countries, and it is a major risk factor for metabolic disorders such as coronary heart disease, hypertension, diabetes, cancer, respiratory diseases, and osteoarthritis [11-13]. Obesity is characterized at the cellular level by an increase in the number and size of adipocytes differentiated from fibroblastic preadipocytes in the adipose tissue [14].

*Address corresponding to this author at the School of Pharmacy, Nihon University, 7-7-1, Narashinodai, Funabashi-shi, Chiba 274-8555, Japan; Tel/Fax: 81-47-465-5985; E-mail: nobushi.yasuhito@nihon-u.ac.jp
Adipocyte differentiation has been extensively examined in cultured preadipocytes such as 3T3-L1 cells. Therefore, 3T3-L1 cells are a suitable model system for obesity related research [15-17].

In this study, we describe the inhibitory effect of Brazilian propolis on intracellular lipid accumulation in 3T3-L1 cells. In particular, the Brazilian propolis AF-08 (BP-AF-08) exhibited a potent inhibitory effect on intracellular lipid accumulation. Moreover, the inhibitory effects of the isolated compounds on intracellular lipid accumulation are also reported.

\section{EXPERIMENTAL METHODS}

\section{Materials}

3T3-L1 fibroblast cells were purchased from the Human Science Research Resources Bank (Osaka, Japan). Isobutyl-3-methylxanthine (IBMX), dexamethasone, insulin, adenine, transferrin, glutamine, and berberine chloride were purchased from Wako Pure Chemical Industries Ltd. (Osaka, Japan). Triiodothyronine was purchased from Sigma-Aldrich Co. (St. Louis, MO, USA). Dulbecco's modified Eagle medium (DMEM) and Ham's F12 medium were purchased from Nissui Pharmaceutical Co., Ltd. (Tokyo, Japan). Calf serum (CS) was purchased from Cell Culture Technologies. Fetal bovine serum (FBS) and Oil Red O were purchased from Cosmo Bio. Co., 
Ltd. (Tokyo, Japan). Penicillin-streptomycin-neomycin (PSN) and penicillin-streptomycin-glutamine (PSG) were purchased from Life Technologies (Burlington, ON). MTT Cell Count Kit (MTT) was purchased from Nacalai Tesque Inc. (Kyoto, Japan).

\section{Brazilian Propolis Samples}

Various Brazilian propolis samples were obtained from Amazonfood Ltd. (Tokyo, Japan). Voucher specimens of proplis (AF-05, AF-06, AFG-06, AF-08, $A F-18, A F-19$, and AF-20) were deposited at the Laboratory of Self Medication, School of Pharmacy, Nihon University (Table 1).

Table 1: Features of Brazilian Propolis

\begin{tabular}{|c|c|c|c|}
\hline Sample & Species $^{\mathbf{a}}$ & Family $^{\mathbf{a}}$ & Area $^{\mathbf{b}}$ \\
\hline \hline AF-05 & $\begin{array}{c}\text { Baccharis } \\
\text { dracunculifolia }\end{array}$ & Compositae & Central \\
\hline AFG-06 & $\begin{array}{c}\text { Baccharis } \\
\text { erioclada }\end{array}$ & Compositae & Southan \\
\hline AF-08 & $\begin{array}{c}\text { Myrcecladia } \\
\text { euosma }\end{array}$ & Compositae & Southan \\
\hline AF-18 & $\begin{array}{c}\text { Baccharis } \\
\text { dracunulifolia }\end{array}$ & Compositae & Central \\
\hline AF-19 & $\begin{array}{c}\text { Baccharis } \\
\text { caprarifolia }\end{array}$ & Compositae & Southan \\
\hline AF-20 & Hyptis divaricate & Labiatae & Southan \\
\hline
\end{tabular}

Note: ${ }^{a}$ Major botanical origins in areas where propolis was collected. ${ }^{\mathrm{b}} \mathrm{Brazilian}$ area where propolis was collected.

\section{Cell Culture}

3T3-L1 preadipocytes were plated in 24-well plates and 6-cm dishes and maintained in DMEM supplemented with $10 \% \mathrm{CS}$ and $1 \% \mathrm{PSG}$ at $37^{\circ} \mathrm{C}$ in a humidified $5 \% \mathrm{CO}_{2}$ incubator. For induction of adipose differentiation, the cells were grown to confluence. The cells were then fed with differentiation medium (2.7:1 mixture of DMEM and Ham's F12 containing 10\% FBS, $1 \%$ PSN, $1.6 \mu \mathrm{M}$ insulin, $0.0005 \%$ transferrin, $180 \mu \mathrm{M}$ adenine, $20 \mathrm{pM}$ triiodothyronine, $0.25 \mu \mathrm{M}$ dexamethasone, and $500 \mu \mathrm{M}$ IBMX. The cells were treated with fresh differentiation medium (for samples) on day 2 and day 4 without dexamethasone and IBMX after induction of differentiation. After 7 days, the cells were fixed on plates with $4 \%$ formalin in phosphatebuffered saline (PBS) for $24 \mathrm{~h}$. The intracellular lipid accumulation was measured 8 days after induction of differentiation. Cell viability was confirmed by microscopic observation and was measured by the MTT assay.

\section{Oil-Red O Staining}

For Oil-red $\mathrm{O}$ staining, cultured cells were fixed on plates with $4 \%$ formalin in PBS for $24 \mathrm{~h}$, rinsed once with $\mathrm{H}_{2} \mathrm{O}$, and then air dried. The fixed cells were stained with Oil-red $\mathrm{O}$ staining solution $(0.5 \%$ Oil-red $\mathrm{O}$ in isopropanol, diluted $3: 2$ in $\mathrm{H}_{2} \mathrm{O}$, and then filtered using a $1.0-\mu \mathrm{m}$ filter) for $15 \mathrm{~min}$. The cells were then rinsed thrice with $\mathrm{H}_{2} \mathrm{O}$ before visualization and documentation.

The density of lipid content was evaluated using AK09F extraction liquid after Oil-red $O$ staining. The absorbance at $540 \mathrm{~nm}$ was measured using a microplate reader. The value of dimethyl sulfoxide (DMSO)-treated cells was normalized to $100 \%$.

\section{Statistical Analysis}

When applicable, results are presented as mean \pm SD. Student's $t$ test was used to calculate $p$ values. Results were considered significant at ${ }^{*} p<0.05,{ }^{* *} p<$ 0.01 , and ${ }^{* *} p<0.001$.

\section{General Experimental Procedure}

The nuclear magnetic resonance (NMR) spectra were measured using a JEOL ECA-600 spectrometer $\left({ }^{1} \mathrm{H}\right.$ NMR: $600 \mathrm{MHz},{ }^{13} \mathrm{C}$ NMR: $150 \mathrm{MHz}$ ) in $\mathrm{CDCl}_{3}$ containing tetramethylsilane (TMS) as the internal standard. The mass spectra were recorded using a JEOL CG mate instrument. High-performance liquid chromatography (HPLC) was performed using a JASCO PU-2089 apparatus equipped with JASCO UV2075.

\section{Extraction and Isolation}

The ethanol extract of the BP-AF-08 $(2.50 \mathrm{~g})$ was fractionated to $n$-hexane-MeOH- $\mathrm{H}_{2} \mathrm{O}$ (19:19:2), which produced $n$-hexane $(0.55 \mathrm{~g})$ and $\mathrm{MeOH}-\mathrm{H}_{2} \mathrm{O}(1.85 \mathrm{~g})$ fractions. The $n$-hexane fraction was purified by HPLC using an InertSustain C18 column $(10 \times 250 \mathrm{~mm}, 5$ $\mu \mathrm{m})$ (GL Sciences Inc., Japan) with $0.1 \%$ trifluoroacetic acid- $\mathrm{CH}_{3} \mathrm{CN}(12: 88 \mathrm{v} / \mathrm{v})$ at a flow rate of $4.0 \mathrm{ml} / \mathrm{min}$, to yield 1 (6.58 mg), 2 (7.02 mg), 3 (5.66 mg), 4 (8.02 $\mathrm{mg})$, and 5 (7.86 $\mathrm{mg})$.

\section{RESULTS AND DISCUSSION}

The seven Brazilian propolis samples were extracted by ethanol, and then the extracts were dried. 


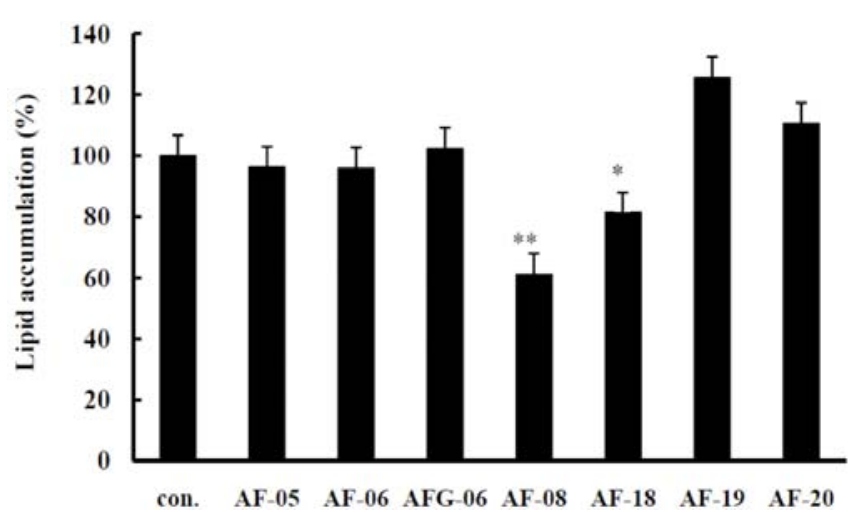

A

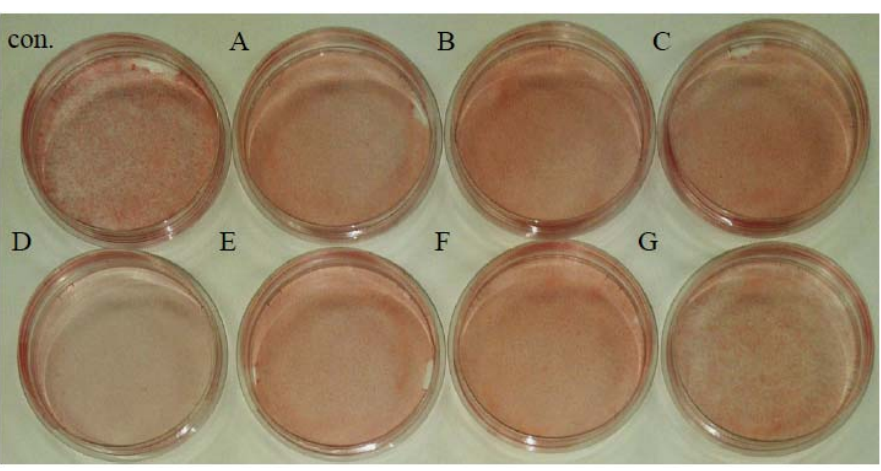

B

Figure 1: A: Effect of Brazilian propolis on lipid accumulation in 3T3-L1 cells. Con, control; A, AF-05; B, AF-06; C, AFG-06; D, AF-08; E, AF-18; F, AF-19; and G, AF-20. Results are expressed as mean \pm SD of three individual experiments. ${ }^{*} p<0.05$ and ${ }^{* *} p<0.01$ vs. control. The value of DMSO-treated cells was normalized to $100 \%$.

B: Oil-red O staining of Brazilian propolis. Con: control; A, AF-05; B, AF-06; C, AFG-06; D, AF-08; E, AF-18; F, AF-19; and G: $A F-20$. Cells were treated with the five fractions $(50 \mu \mathrm{g} / \mathrm{ml})$ on day 2 and day 4 . The intracellular lipid content was measured 8 days after induction of differentiation.

The cytotoxicity of the seven extracts was evaluated by the MTT assay in 3T3-L1 cells and all the extracts were found to be nontoxic at $50 \mu \mathrm{g} / \mathrm{ml}$ (data not shown). The seven Brazilian propolis extracts were tested to verify inhibitory effects on intracellular lipid accumulation (Figure 1A). Lipid accumulation assay results demonstrated that the BP-AF-08 and AF-18 had an inhibitory effect on intracellular lipid accumulation. In particular, the BP-AF-08 exhibited a potent inhibitory effect on intracellular lipid accumulation. As presented in Figure 1B, the differentiation of the BP-AF-08 was inhibited compared to the other Brazilian propolis, as determined oil-red $\mathrm{O}$ staining. These results indicate that the BP-AF-08 contributes to the prevention of metabolic syndrome. Therefore, we focused our efforts on investigating the chemical constituents of the BPAF-08.

Five known triterpenoids were isolated from the BPAF-08 (Figure 2). Identification of the five triterpenoids, betulonic acid (1) [18], moronic acid (2) [18, 19], 3-oxo oleanolic acid (3) [20], masticadienonic acid (4) [21],

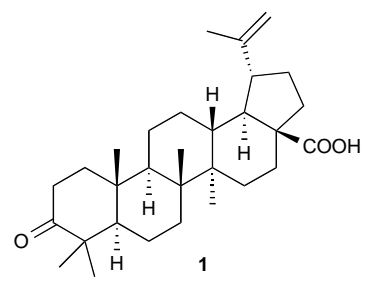

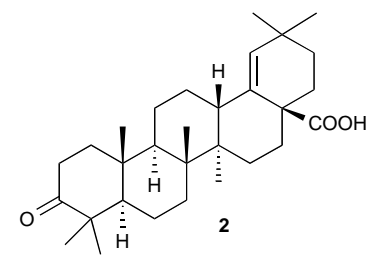
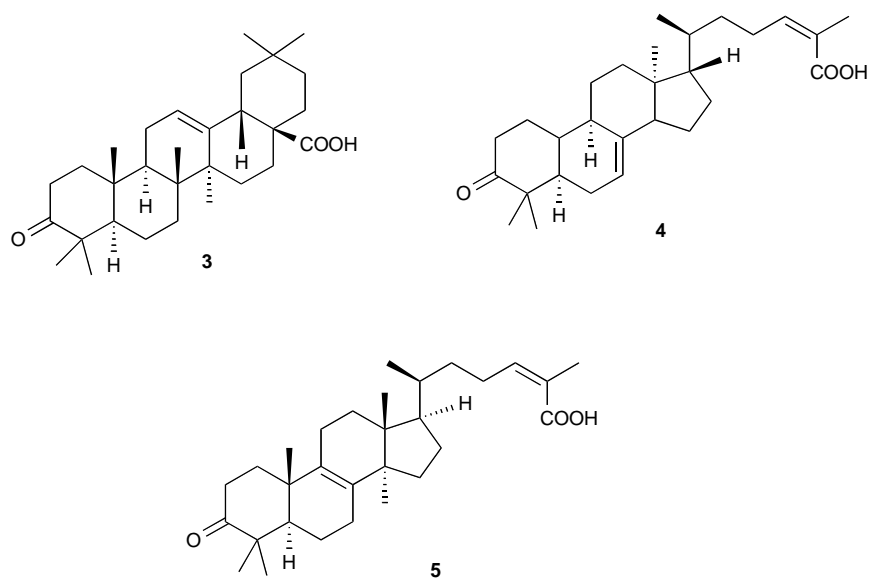

Figure 2: Structures of compounds 1-5. 1, betulonic acid; 2, moronic acid; 3, 3-oxo-oleanolic acid; 4, masticadienoic acid; and 5, anwuweizonic acid. 


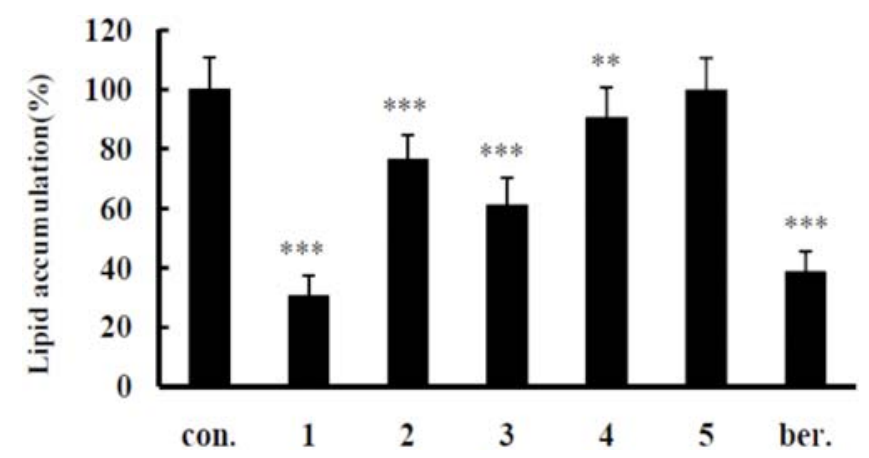

A

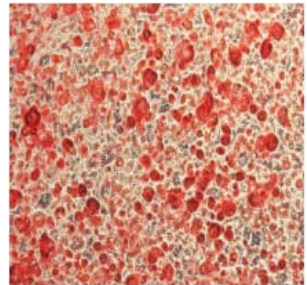

con.

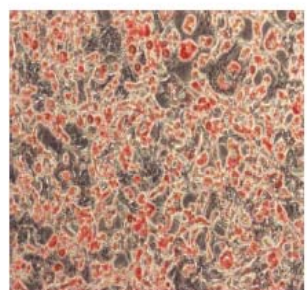

3

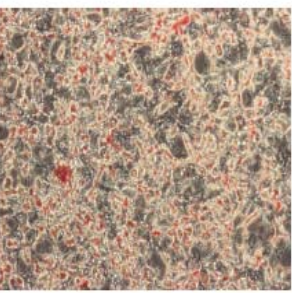

ber.

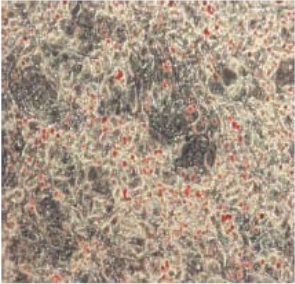

1

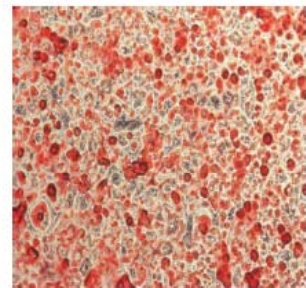

4

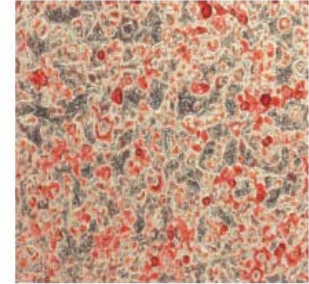

2

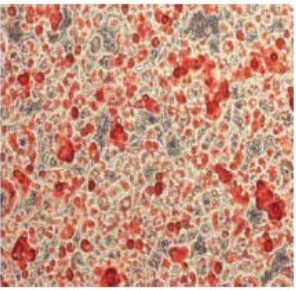

5

B

Figure 3: A: Effect of triterpenoids 1-5 on lipid accumulation in 3T3-L1 cells. Con, control; 1, betulonic acid; 2, moronic acid; 3, 3-oxo oleanolic acid; 4, masticadienonic acid; and 5, anwnweizonic acid; ber., berberine chloride. Results are expressed as mean \pm SD of three individual experiments. ${ }^{*} p<0.05$, ${ }^{* *} p<0.01$, and ${ }^{* * *} p<0.001$ vs. control. The value of DMSO-treated cells was normalized to $100 \%$.

B: Ablation of control, five triterpenoids, and berberine by Oil-red O staining. Con, control; 1, betulonic acid; 2, moronic acid; 3, 3oxo oleanolic acid; 4, masticadienonic acid; 5, anwnweizonic acid; and ber, berberine chloride.

and anwnweizonic acid (5) [18] was performed by a spectral comparison with literature data. Full details of the isolation and identification as well as the spectroscopic data are available on request from the corresponding author. The inhibitory effect of the five triterpenoids on intracellular lipid accumulation was examined. Berberine chloride was used as a positive control as it has been reported to have inhibitory effects on intracellular lipid accumulation [22]. The cytotoxicity of the five compounds was evaluated by the MTT assay in 3T3-L1 cells. The results indicated that the five compounds were nontoxic at concentrations up to $30.0 \mu \mathrm{M}$. Our results demonstrated that the five triterpenoids inhibited intracellular lipid accumulation at $30 \mu \mathrm{M}$ (Figure 3A). As presented in Figure 3B, ablation of five triterpenoids, berberine chloride, and untreated 
control resulted in inhibited lipid accumulation as shown by oil-red $O$ staining. Anwnweizonic acid (5) exhibited less inhibitory effect on lipid accumulation. Moronic acid (2), 3-oxo oleanolic acid (3), and masticadienonic acid (4) exhibited a minimum inhibitory effect on lipid accumulation comparable with that of the positive control. Betulonic acid (1) was more effective than the other triterpenoids. As presented in Figure 4, betulonic acid inhibited lipid accumulation in a concentration-dependent manner.

Recent studies have attempted to investigate the beneficial effects of lupeol and lupenone on intracellular lipid accumulation in 3T3-L1 cells [23, 24]. Our results indicate that triterpenoids may be important as antiobesity agents that inhibit the metabolic syndrome.

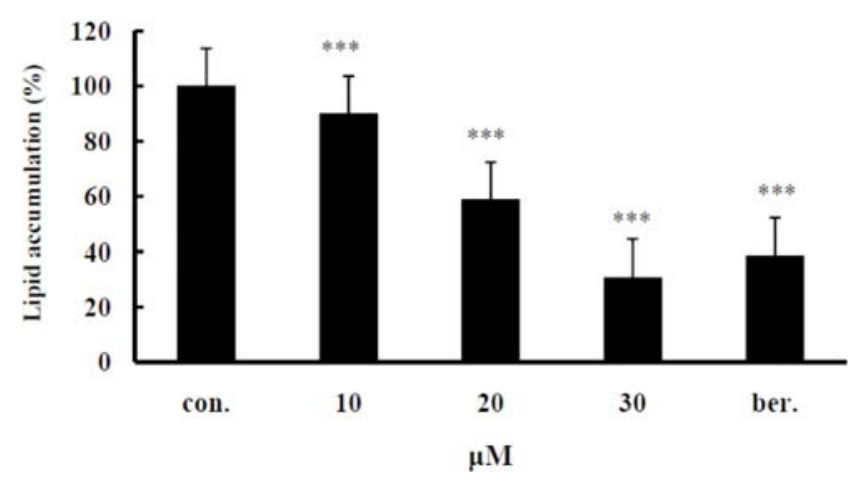

Figure 4: Betulonic acid (1) has a concentration-dependent effect on lipid accumulation in 3T3-L1 cells. Results are expressed as the means \pm SD of three individual experiments. ${ }^{*} p<0.05,{ }^{* *} p<0.01$, and ${ }^{* * *} p<0.001$ vs. control. The value of DMSO-treated cells was normalized to $100 \%$.

\section{CONCLUSION}

We here investigated the inhibitory effect of various Brazilian propolis on intracellular lipid accumulation. In general, the chemical composition of Brazilian propolis depends on the vegetation of the area from where it is harvested. Lipid accumulation assay results demonstrated that the BP-AF-08 and AF-18 had inhibitory effects on intracellular lipid accumulation. In particular, the BP-AF-08 exhibited a potent inhibitory effect on intracellular lipid accumulation. Thus, our results suggest that the BP-AF-08 contributes to the prevention of metabolic syndrome. In addition, five known triterpenoids were isolated from the BP-AF-08. Four triterpenoids: betulonic acid (1), moronic acid (2), 3-oxo oleanolic acid (3), and masticadienonic acid (4) exhibited an inhibitory effect on the intracellular lipid accumulation. Furthermore, betulonic acid (1) exhibited the highest inhibitory effect on intracellular lipid accumulation as well as positive control. These results indicate that triterpenoids may be the source of antiobesity agents to improve the metabolic syndrome.

\section{ACKNOWLEDGEMENTS}

This study was supported in part by a joint research grant from Nihon University School of Pharmacy.

\section{REFERENCES}

[1] Ghisalberti EL. Propolis: a review. Bee World 1979; 60: 5984.

[2] Marcucci MC. Propolis: Chemical composition, biological properties and therapeutic activity. Apidologie 1995; 26: 8396.

http://dx.doi.org/10.1051/apido:19950202

[3] Kumazawa S, Yoneda M, Shibata I, et al. Direct evidence for the plant origin of Brazilian propolis by the observation of honeybee behavior and phytochemical analysis. Chem Pharm Bull 2003; 51 (6): 740-742.

http://dx.doi.org/10.1248/cpb.51.740

[4] Scazzocchio F, D'Auria FD, Alessandrini D, et al. Multifactorial aspects of antimicrobial activity of propolis. Microbiol Res 2006; 161: 327-333. http://dx.doi.org/10.1016/j.micres.2005.12.003

[5] Shimizu T, Hino A, Tsutsumi A, et al. Anti-influenza virus activity of propolis in vitro and its efficacy against influenza infection in mice. Antivir Chem Chemother 2008; 19 (1): 7-13.

[6] Tan-no K, Nakajima T, Shoji T, et al. Anti-inflammatory effect of propolis through inhibition of nitric oxide production on carrageenin-induced mouse paw edema. Biol Pharm Bull 2006; 29 (1): 96-99.

http://dx.doi.org/10.1248/bpb.29.96

[7] Murad JM, Calvi SA, Soares AMVC, et al. Effects of propolis from Brazil and Bulgaria on fungicidal activity of macrophages against Paracoccidioides brasiliensis. J Ethnopharmacol 2002; 79: 331-334.

http://dx.doi.org/10.1016/S0378-8741(01)00404-4

[8] Shimizu K, Ashida $\mathrm{H}$, Matsuura $\mathrm{Y}$, et al. Antioxidant bioavailability of artepillin-C in Brazilian propolis. Arch Biochem Biophys 2004; 424: 181-188. http://dx.doi.org/10.1016/j.abb.2004.02.021

[9] Nakajima Y, Shimazawa M, Mishima S, et al. Water extract of propolis and its main constituents, caffeoylquinic acid derivatives, exert neuroprotective effects via antioxidant actions. Life Sci 2007; 80: 370-377. http://dx.doi.org/10.1016/j.lfs.2006.09.017

[10] Izuta $H$, Narahara $Y$, Shimazawa $M$, et al. 1,1-Diphenyl-2picrylhydrazyl radical scavenging activity of bee products and their constituents determined by ESR. Biol Pharm Bull 2009; 32 (12): 1947-1951.

http://dx.doi.org/10.1248/bpb.32.1947

[11] Kopelman PG. Obesity as a medical problem. Nature 2000; 404: 635-643.

[12] Mann CC. Public health: provocative study says obesity may reduce U.S. life expectancy. Science 2005; 307: 1716-1717. http://dx.doi.org/10.1126/science.307.5716.1716

[13] Ito $M$, Ito $J$, Kitazawa $H$, et al. (-)-Ternatin inhibits adipogenesis and lipid metabolism in 3T3-L1 cells. Peptides 2009; 30: 1074-1081. http://dx.doi.org/10.1016/j.peptides.2009.02.008

[14] Furuyashiki T, Nagayasu H, Aoki $\mathrm{Y}$, et al. Tea catechin suppresses adipocyte differentiation accompanied by downregulation of PPARY2 and C/EBPa in 3T3-L1 cells. Biosci Biotechnol Biochem 2004; 68: 2353-2359. http://dx.doi.org/10.1271/bbb.68.2353 
[15] Ahn J, Lee H, Kim S, Park J, Ha T. The anti-obesity effect of quercetin is mediated by the AMPK and MAPK signaling pathways. Biochem Biophys Res Commun 2008; 373: 597608.

http://dx.doi.org/10.1016/j.bbrc.2008.06.077

[16] Wada T, Ihunnah CA, Gao J, et al. Estrogen sulfotransferase inhibits adipocyte differentiation. Mol Endocrinol 2011; 25: 1612-1623.

http://dx.doi.org/10.1210/me.2011-1089

[17] Yahagi T, Daikonya A, Kitanaka S. Flavonol acylglycosides from flower of Albizia julibrissin and their inhibitory effects on lipid accumulation in 3T3-L1 cells. Chem Pharm Bull 2012; 60: $129-136$

http://dx.doi.org/10.1248/cpb.60.129

[18] Ito J, Chang FR, Wang HK, et al. Anti-AIDS agents. 48.AntiHIV activity of moronic acid derivatives and the new melliferone-related triterpenoid isolated from Brazilian propolis. J Nat Prod 2001; 64: 1278-1281.

http://dx.doi.org/10.1021/np010211x

[19] Zhang P, Hao J, Liu J, et al. Efficient synthesis of morolic acid and related triterpenes starting from betulin. Tetrahedron 2009; 65: 4304-4309.

http://dx.doi.org/10.1016/j.tet.2009.03.100
[20] Konoike T, Takahashi K, Araki Y, et al. Practical partial synthesis of myriceric acid $A$, an endothelin receptor antagonist, from oleanolic acid. J Org Chem 1997; 62: 960966.

http://dx.doi.org/10.1021/j09615864

[21] Mulholland D A, Nair JJ. Triterpenoids from dysoxylum pettigrewianum. Phytochemistry 1994; 37 (5): 1409-1411. http://dx.doi.org/10.1016/S0031-9422(00)90421-7

[22] Huang $C$, Zhang Y, Gong Z, et al. Berberine inhibits 3T3-L1 adipocyte differentiation through the PPARy pathway. Biochem Biophys Res Commun 2006; 348: 571-578. http://dx.doi.org/10.1016/j.bbrc.2006.07.095

[23] Hata K, Hiwatashi K, Itoh M, et al. Inhibitory effects of lupeol on 3T3-L1 preadipocyte differentiation. Phytochem Lett 2008 1: 191-194. http://dx.doi.org/10.1016/j.phytol.2008.09.007

[24] Ahn EK, Oh JS. Lupenone isolated from adenophora triphylla var. japonica extract inhibits adipogenic differentiation through the downregulation of PPARy in 3T3-L1 cells. Phytother Res 2013; 27: 761-766. http://dx.doi.org/10.1002/ptr.4779 